\section{Stemming doublespeak}

Self-deception is part of being a modern Homo sapiens. We shun the seasonality of unadventurous local produce yet are surprised that the constancy of exotic fruits and vegetables comes at a cost measured in fuel use and environmental damage. We crave affordable running shoes, but rail at capitalist structures built on teenage sweatshops. Meat eaters rarely consider the abattoir when their knives cut the succulent filet.

In science, the "Nike paradox" thrives. Indeed, it is legally enshrined. One current example involves government attitudes to human embryonic stem (ES) cells. In the US, for instance, the National Institutes of Health (NIH) wants to be able to fund researchers to work on human ES cells, but it also seems to want to detach itself from the origins of those cells in aborted embryos. The influence of antiabortion, "pro-life" groups has meant that for the past 20 years US federal policy has prohibited all funding of research on human fetal tissue and embryos. No such constraints exist for private companies.

Presently, various scientific bodies are going through all kinds of contortions to try to move the situation forward. NIH, for instance, believes it is already entitled to fund human pluripotent stem cell research. Last year, Harriet Rabb, general counsel for the Department of Health and Human Services, reexamined the legal position and concluded that the statutory prohibition on federally funded embryo research did not apply to stem cell studies. Thus armed, former NIH director Harold Varmus announced that NIH funds would be made available for ES cell research.

However, federal researchers are still forbidden from working on embryos and, like the anatomists of the 19th century, will have to buy the stem cells from privately funded companies, who do the "dirty work." Apparently, neither the NIH nor the American Association for the Advancement of Science has any problems with this double standard, even though research in the private sector is hidden from the rigors of federal oversight or external scrutiny, and is often unverified by peer review and publication.

The US Stem Cell Research Act of 2000 (S. 2015) is slated for imminent debate on the floor of the US Senate. Importantly, this bill not only sanctions funding of ES cells, but also their derivation from embryos that otherwise would be discarded. We fully support this bill and urge the community to prevail upon politicians to ensure that it is passed. Failing that, the NIH must stand up and strenuously lobby for funding to be made available for deriving stem cells as well as studying them.

\section{In praise of pessimism}

A cardinal scientific principle (if not always a strictly observed practice) is that sources of experimental bias should be eliminated if possible or (if they are not) at least explored and acknowledged. The truth is that instances where this apparently universally accepted precept is ignored are commonplace when even well-intentioned scientists undertake goal-directed research.

There are many illustrations in biotechnology of the distorting influence of the goal. It was only in April this year that the American Society of Gene Therapy (ASGT; founded in 1996) instituted its policy that "all investigators and team members directly responsible for patient selection, the informed-consent process, and/or clinical management in a trial must not have equity, stock options, or comparable arrangements in companies sponsoring the trial." The guiding principle behind the new policy is that investigators "must be able to design and carry out clinical research studies in an objective and unbiased manner." The need to eliminate such influence over clinical proceedings ought surely to have been so obvious as to be not worth saying.

There may be no causal relationship, but the ASGT's call for clinical clarity follows reports that researchers have been underreporting "adverse events" in gene therapy trials. Until November 1999, only 39 adverse events had been reported to the NIH from a group of 93 gene therapy studies. After a stern reminder from the NIH following the death of one patient at a trial at the University of Pennsylvania, however, over 650 additional such events have been reported from the same 93 studies. These data imply that gene therapy researchers do not relinquish bad news gladly.

The trouble with goal-directed research is that the goal acts like a magnet, drawing the focus of attention in one direction rather than another. The magnet can be a positive aid to efficiency, determining which experiments should be performed and on what time scale. Polarizing the direction of research is not necessarily a bad thing; polarizing the interpretation of results clearly is. A negative result ought to be as valuable as a positive one. In reality, however, it rarely is. It is not valuable in advancing a carefully constructed theory. It is not valuable in addressing a goal. It is not valuable in impressing your boss, or the CEO, or the shareholders.

Perhaps it can be argued that gene therapy is a special case. After all, the technique is often applied to a small number of otherwise incurable patients in trials that may not be placebo-controlled by companies that are as reliant as the patients on success outcomes for their own survival. However, that would be to ignore clear data elsewhere. On numerous occasions, biotechnology companies have propelled high-profile lead molecules along clinical paths that were unjustified by data. Biotechnology companies take a higher ratio of their compounds into clinical trials; they propel proportionally more of them through phase II, and they lose proportionally more after or during phase III. In some cases, sales forces have been hired and manufacturing facilities built in anticipation of drug approvals that never came or were rescinded.

Yes, the achievements of biotechnology have been both many and praiseworthy. But the net result of a cloyingly positive attitude to drug development that can be endemic in close-knit, team-oriented companies is that fewer useful treatments have emerged than should have. Unjustified optimism is both dishonest and costly. Unmet medical needs remain unmet. It wastes investors' money and investigators' time and leaves other avenues unexplored. 